\title{
LOS PROBLEMAS DE LOS PODERES EX OFFICIO DEL JUEZ LABORAL. AHORA A PROPÓSITO DE LA POTESTAD CONCILIATORIA*
}

\author{
Diego Palomo Vélez** \\ Pedro Matamala Souper***
}

\section{Sentencia de la Corte de Apelaciones de Santiago}

Santiago, once de noviembre de dos mil once.

Vistos y teniendo presente:

$\left.1^{\circ}\right)$ Que se ha deducido recurso de nulidad por la trabajadora demandante en procedimiento monitorio, fundado en lo principal en la causal del artículo 478 letra a) del Código del Trabajo, esto es, haberse dictado la sentencia por juez legalmente implicado, al tenor del motivo de inhabilidad del artículo 195 numeral $8^{\circ}$ del Código Orgánico de Tribunales, es decir, por haber manifestado anticipadamente su dictamen sobre la cuestión pendiente, con conocimiento de los antecedentes necesarios para dictar sentencia.

En subsidio, por la causal del artículo 477 del mismo cuerpo legal, por haberse infringido -en la tramitación del procedimiento- la garantía o derecho constitucional a un proceso legalmente tramitado, racional y justo.

En subsidio, por la causal genérica del mismo artículo 477, en cuanto se habría incurrido en infracción del artículo 183-A el mismo cuerpo legal, la que ha influido sustancialmente en lo dispositivo del fallo.

$2^{\circ}$ ) Que a guisa de explicación y antecedentes del recurso, la recurrente ha expresado: A) Que fue despedida con fecha 31 de octubre de 2010, no obstante hallarse protegida con el fuero de maternidad establecido por el artículo 201 del Código Laboral, luego del nacimiento de su hija, acaecido el día 5 de febrero de 2010. B) Que en el contexto del procedimiento monitorio respectivo -obligatorio por mandato del artículo 496 del mismo cuerpo legal- habiendo

\footnotetext{
*Trabajo forma parte de Proyecto Fondecyt Regular 2012 №1120409, "Estudio crítico del nuevo proceso laboral chileno a la luz de las exigencias del derecho al debido proceso". Trabajo recibido el 17 de abril y aprobado el 27 de abril de 2012.

** Abogado; profesor de Derecho Procesal en la Universidad de Talca; Magíster y Doctor en Derecho por la Universidad Complutense de Madrid, España. Correo electrónico: dpalomo@utalca.cl.

*** Abogado; profesor de Litigación oral en la Universidad de Talca; Magíster en Derecho del Trabajo por la misma Universidad. Correo electrónico: pedro.matamala@hmv.cl.
} 
deducido la reclamación del inciso segundo de su artículo 500, se fijó audiencia única de conciliación, contestación y prueba, para el día 21 de febrero de 2011, en el transcurso de la cual se habría incurrido por el sentenciador a quo en las conductas inhabilitantesque señala, analizadas en el Considerando siguiente.

$\left.3^{\circ}\right)$ Que a lo largo de toda la audiencia referida, el juez a quo habría mantenido una actitud agresiva, intimidante y carente de ecuanimidad, comprometedora de la necesaria imparcialidad exigible a su cometido jurisdiccional, tomando partido anticipada y arbitrariamente en la litis.

Dice, en efecto: A) Que durante todo el curso de la audiencia, y no sólo en la fase de conciliación, instó reiterativamente a su parte a desistirse de su reclamación; B) Que para ello, adujo que él ya había fallado varias veces en la misma materia, en cuanto consideraba improcedente la dicha reclamación, porque el trabajo de la actora como administradora de contratos de la demandada principal, con facultades de dirigir, contratar y despedir personal, excluía absolutamente un eventual vínculo laboral de subcontratación con las otras demandadas, razón por la cual iba a rechazar la demanda a sus respectos; C) Que incluso habría expresado de viva voz que "no le temblaría la mano para condenar en costas a la demandante"; D) Que, además, se habría jactado de la inutilidad de un eventual recurso de nulidad, atendida la claridad de sus fallos, y la circunstancia de no tener que hacerse cargo de la prueba rendida en este procedimiento monitorio; E) Que todo lo anterior habría sido dicho en tono agresivo, hostil e intimidatorio; F) Que nada o casi nada de todo lo dicho se refleja en la grabación del sistema de audio, desconectado precisamente en los pasajes mencionados.

$\left.4^{\circ}\right)$ Que en la vista de la causa, el propio letrado que alegó por las demandadas recurridas, si bien negó que el juez a quo hubiere anticipado su resolución del juicio, reconoce que el magistrado se expresaba "a lo mejor en forma violenta".

$5^{\circ}$ ) Que en la vista del recurso, el mismo letrado admite que "hay partes de la audiencia que no aparecen en el audio... nada de esto aparece"; y que el juez llamó a la actora a desistirse, razón por la cual, a su juicio, la demandante habría debido solicitar en el acto la inhabilitación del magistrado.

$\left.6^{\circ}\right)$ Que la conducta magisterial descrita, así reconocida incluso por la contraparte de la recurrente, amén de configurar la causal de implicancia del numeral $8^{\circ}$ del citado artículo 195 del Código Orgánico de Tribunales, resulta del todo impropia e inaceptable, porque además de ser lesiva de los principios de inmediación y transparencia del procedimiento laboral vigente, vulnera la garantía de mesura, prudencia, racionalidad y -por sobre todo- imparcialidad del juzgador, esto es, la del proceso justo y racional a que se refiere el numeral $3^{\circ}$ del artículo 19 de la Carta Fundamental.

Por estas consideraciones, normas legales citadas y demás pertinentes del Código Laboral, se acoge el recurso de nulidad deducido por la parte de doña 
Maribel Andrea Venegas Guzmán, anulándose todo lo obrado en el procedimiento monitorio RIT M-71- 2011 del Segundo Juzgado de Letras del Trabajo de Santiago, a partir de la audiencia de 21 de febrero de 2011, debiendo quedar dichos autos en estado de fijarse día y hora para la celebración de la audiencia única de conciliación, contestación y prueba, por el juez no inhabilitado que corresponda.

Atendida la gravedad de los hechos enunciados, pasen los antecedentes al Pleno de esta Corte de Apelaciones de Santiago, para los fines a que haya lugar.

Regístrese y comuníquese.

No Reforma Laboral 396-2011.

Redacción del Abogado Integrante señor Antonio Barra Rojas.

Pronunciada por la Décima Sala de esta Corte de Apelaciones de Santiago, presidida por el Ministro señor Juan Manuel Muñoz Pardo, e integrada por el Ministro señor Jorge Zepeda Arancibia y por el Abogado Integrante señor Antonio Barra Rojas.

\section{Sobre LOS Objetivos asociados a la ReFORMA PROCESAl LABORAL, LA ORALIDAD Y UN ENFOQUE UNIDIRECCIONAL DE LA EFICIENCIA}

Hemos revisado y analizado antes, a propósito de otra sentencia, los necesarios límites que debe tener el juez del trabajo al momento de ejercer sus potestades ex officio en materia de prueba ${ }^{1}$. Pues bien, la sentencia que ahora analizamos nos coloca en la línea de otro de los temas de alta discusión actual, y que se refiere a la extensión de los poderes de conciliación del juez en el nuevo proceso laboral chileno, y cómo el ejercicio concreto de estos poderes oficiosos consigue afectar su debida imparcialidad, pudiendo incluso llegar a comprometer la validez de lo obrado y resuelto.

Lo primero que debe tenerse en cuenta en punto a la realización de este análisis es tener a la vista cuál es la función de la jurisdicción y el fin del proceso. Somos de la idea que la tutela y realización del Derecho objetivo es contenido de la función jurisdiccional, pero teniendo presente que la jurisdicción se excita justamente a propósito de existir una contienda entre partes que debe ser resuelta para lograr establecer la paz social. La jurisdicción, entonces, y más allá de las consideraciones más o menos compartidas en la dogmática procesal, está llamada a resolver las contiendas, para lo cual se recurre al mecanismo del proceso que se sostiene y levanta, como lo hemos venido recordando cada vez que tenemos oportunidad, en un puñado de postulados elementales de justicia que deben cumplirse necesariamente. Entre ellos se deben contar siempre la

${ }^{1}$ Véase: Palomo Vélez, D.; Matamala Souper, P., "Juez y Parte. El compromiso espiritual del juez en el interrogatorio de testigos en el juicio laboral oral y sus necesarios límites", Revista lus et Praxis, Año $17 \mathrm{~N}^{\circ} 2,2011$, pp. 485 y ss. 
imparcialidad, la igualdad de armas, y los principios de audiencia, de contradicción y de moralidad del debate. Tan relevante es su presencia y respeto que sin ellos el instrumento creado por el legislador, por abundante que sea la buena voluntad que pueda existir, dejaría de ser un cauce adecuado para la tutela de los derechos de los ciudadanos e instrumento lógico de la jurisdicción. Esta simple cuestión, fruto de la evolución y desarrollo del Derecho procesal, viene siendo olvidada por nuestro legislador al descuidar en su diseño los necesarios equilibrios y resguardos para los intervinientes.

Lo segundo, pero estrechamente ligado, es tener a la vista los objetivos fundamentales de la reforma procesal laboral, y las consecuencias (algunas de ellas dañosas) que se empiezan a reproducir en este orden jurisdiccional, producto de decisiones relativas al modelo procesal que parecen haberse asumido con desbordes innecesarios y desafortunados. Trátase, como se sabe, de un modelo que toma partido por la extendida fórmula de la oralidad. En efecto, desde el denominado modelo de proceso por audiencias, la oralidad y sus reglas asociadas aparecen contempladas con un papel que viene a ser preponderante a la hora de lograr una renovada Justicia laboral, sobre todo más eficiente. Pues bien, la cuestión de la búsqueda de esta eficiencia, en el caso del proceso de reforma al orden jurisdiccional laboral (también en el caso de la reforma a los tribunales de familia) ha sido vinculadacasi unidireccionalmente con el mejoramiento en el tiempo de duración de los procesos que, con el sistema procesal derogado, no cumplían con un estándar razonable, reflejándose en la dilación con la que los tribunales brindaban respuesta a los justiciables, cuestión especialmente problemática si se considera la naturaleza de una buena parte de los conflictos que se someten a la decisión de la judicatura laboral.

Con todo, es nuestro parecer que la búsqueda de una mayor eficiencia en la Justicia no debe agotarse ni circunscribirse en un mejoramiento de las estadísticas del factor tiempo, pues, además de generar estímulos peligrosos en algunos jueces poderosos pero poco prudentes, muchas veces puede esconderse un deficitario desempeño en cuanto a otro de los aspectos que no debemos perder de vista jamás: la calidad del servicio a la justicia y del producto de la jurisdicción. Lo que queremos dejar establecido como sustento de nuestra posición sobre el reformado modelo procesal laboral es que, incluso por sobre otro orden de consideraciones (como lo puede ser el elemento tiempo), la apuesta por la oralidad, la concentración y la inmediación judicial debiera estar dirigida muy fundamentalmente a la configuración de un modelo procesal más razonable y serio. En efecto, un modelo como el asumido por nuestro legislador, que se sostenga con estas características formales debe apostar especialmente por la recuperación de la seriedad objetiva en el ejercicio de la función jurisdiccional, y en lo que debiera ser consecuencia natural de ello, por el logro de un mejor servicio de justicia y un mejor producto jurisdiccional. 


\section{El mOdelo Del NUEVO JUEZ LABORAL: REFORZADísimas POTESTADES EX OFFICIO} COMO CONSECUENCIA DEL NUEVO MODELO PROCESAL

Se plantea, entonces, que sólo apostando por el reforzamiento de las potestades de los jueces nos lograremos acercar a una real modernidad y progresismo procesal. Si para lograrlo la regulación de las garantías procesales debe operar a la baja (reformatio in peius), se asume que es el costo que debe pagarse para lograr un verdadero cambio hacia un mejor modelo de enjuiciamiento, moderno y justo. Se instala entre nosotros la peligrosa idea que las garantías procesales, las partes y sus abogados, constituyen un obstáculo para los fines de la jurisdicción, del proceso y de la prueba, llegándose a tolerarse por varios sin mayores cuestionamientos una noción que en Derecho debiera resultar inadmisible, esto es, que el fin justifica los medios.

Somos de aquellos que consideran que el legislador no puede hacer tabla rasa o regular a la baja las garantías procesales, ni aun a pretexto de buscar conseguir determinados objetivos que se declaran valiosos. Parece olvidarse que el proceso, como construcción artificial del legislador que es (siguiendo a Carreras), debe respetar algunos postulados elementales que tienen un carácter necesario, de modo que sin ellos, el producto de la labor realizada por el legislador podrá terminar siendo cualquier cosa, pero no logrará configurar un verdadero proceso. No entenderlo de este modo, es olvidar que en Derecho un buen fin no basta para justificar los medios empleados para conseguirlo. Es, al final del día, abandonar la noción de proceso como garantía.

Las razones que se esgrimen a favor de este reforzamiento ligan fundamentalmente con dos objetivos: lograr establecer la verdad de los hechos sometidos a juzgamiento, que se estima presupuesto indispensable para una sentencia que resuelva el conflicto de forma justa, y la necesidad que existiría de brindar asistencia de la parte más débil. La búsqueda de ambos obligarían a reforzar la intervención del juez, adoptando de oficio las medidas de dirección necesarias para el válido, eficaz y pronto desarrollo del proceso (que se llaman potestades procesales) y decretando diligencias de prueba para el esclarecimiento de la verdad de los hechos, e incluso a través de la posibilidad de distribuir la carga de la prueba conforme a la disponibilidad y facilidad probatoria de las partes, según principios de justicia, cooperación y buena fe procesal (en lo que serían potestades materiales), dejando de lado incluso normas garantistas de resguardo de los derechos de las partes para controlar la actuación del juez y la fiabilidad de la información que se ingresa al proceso.

Lo cierto es que no es muy difícil imaginar que planteados de esa forma los objetivos la crítica llegue en una doble dirección. En primer lugar, en lo que liga con la verdad como objetivo, parece extraño que se haga referencia a ella con tanta liviandad, minimizando o ignorando las dificultades que ella 
puede encontrar en el ámbito del proceso en general y del proceso laboral en particular. Para conseguir la verdad el juez no debiera tener en esta tarea de cognición ningún límite, y ello no puede entenderse ser así ni aun en el proceso laboral, ya que exigiría pasar por alto una serie de necesarios límites impuestos por la idea misma de proceso. En segundo lugar, se omite que encargarle al juez la asistencia del que se considera débil es sacrificar su imparcialidad, permitiéndole que se comporte como si fuese una parte más (pero con poderes superiores), desechando que esa preocupación puede materializarse por otras vías, sin arriesgar este principio tan claro de todo proceso.

En este afán de suscribir estas posturas especialmente cautivadas por el reforzamiento de las potestades de los jueces en el proceso laboral se arriesga la imparcialidad, se contribuye a la arbitrariedad y se pone serios obstáculos a la calidad y fiabilidad de la información que se incorpora al juicio y sirve de sustento a la sentencia. Se configura y asume un modelo en el cual se confía desbordadamente en lo que hacen los jueces de la instancia, los que por el solo hecho de ser tales, estarían guiados por un propósito de búsqueda de la decisión justa amparada en la verdad. Correspondería confiar en la creatividad, criterio y libertad de los jueces, sin límites, ya que lo que importa es la meta, determinar la verdad de los hechos, y a partir de ello lograr la decisión justa.

Creemos que la experiencia acumulada hasta la fecha en los nuevos juicios laborales, la realidad del comportamiento de no pocos jueces de esta jurisdicción (donde los hechos que describe la sentencia en comento son un ejemplo), desaconsejanseguir operando sin límites ni contrapesos respecto de las potestades judiciales ex officio. El resultado que se logra es que el juez termina apropiándose del proceso asumiendo el rol de litigante, brillando por ausencia los límites y contrapoderes de las verdaderas partes, afectándose de esta manera los postulados elementales de un proceso, el derecho de defensa de las partes y también la seriedad objetiva en el ejercicio de la función jurisdiccional por las conductas de jueces que en no pocas ocasiones dejan de comportarse como tales, sustituyéndose en una labor que corresponde a las partes, las que al final pierden toda relevancia. La búsqueda de una difusa meta justiciera termina hiriendo gravemente la imparcialidad del tribunal, abriendo la puerta a la arbitrariedad y comprometiendo la calidad y fiabilidad de la información que se inserta en el proceso y que sirve de base para el pronunciamiento de la sentencia, situación que se cierra a través de la consagración de un modelo recursivo restringido que reemplaza al recurso de apelación por un recurso de nulidad materializando un retroceso en el sistema de garantías.

Se hace necesario definir límites a las potestades judiciales ex officio; los jueces no pueden asumir un protagonismo que llegue a ser sustitutivo de las partes en materia de los hechos y su prueba. Tampoco en la aplicación del derecho, en dónde el poder del juez no puede ser absoluto y sin límites al hilo de 
la máxima iuranovit curia, sino que debe cuidarse de no afectar el derecho de defensa a través, por ejemplo, de una sorpresiva calificación jurídica recogida en la sentencia, respecto de la cual la parte no haya podido argumentar durante el proceso. En definitiva, el rescate del juez, su labor, y de la imagen de la Justicia, a través de la fórmula de la oralidad, no debe autorizar vaciar de contenido algunos de los postulados mínimos sobre los cuales se levanta la idea misma de proceso, dado que en el afán de poner fin a una crisis de la eficiencia de la Justicia podemos caer en otra, la crisis de la seriedad de la función jurisdiccional y de la calidad del servicio Justicia que surge de la creencia, ya instalada en la jurisdicción laboral criolla, de que el juez hace justicia a pesar de las partes que intervienen en el proceso.

\section{A PROPÓSITO DE LA POTESTAD CONCILIATORIA DE LOS JUECES: OtRA FUENTE DE} PROBLEMAS POR LOS EXCESOS. CONSIDERACIONES CRÍTICAS A PARTIR DEL FALLO DE LA I.

\section{CORTE DE APELACIONES DE SANTIAGO}

Hemos señalado antes que se postula que una decisión será justa sólo cuando se base en el establecimiento de la verdad de los hechos, poniendo el acento en la meta y regulando a la baja las reglas propias que dan contenido a un proceso justo, que es lo que, a nuestro juicio, acontece a propósito de la reforma procesal laboral. Con todo, más allá de este declarado soporte ideológico que sustenta al nuevo modelo de enjuiciamiento laboral, lo cierto es que uno de sus pilares viene dado por un reforzamiento de la función conciliatoria, desde la cual se busca brindar una efectiva salida alternativa a la sentencia a los justiciables, adelantando aún más una solución del conflicto. ${ }^{2}$ De este modo, consciente o inconscientemente, nuestro legislador ha introducido reforzadamente un mecanismo que no apunta ya a la búsqueda y determinación de la verdad de los hechos, sino que al restablecimiento de la paz social que va cobrando importante protagonismo a través del fomento de los mecanismos alternativos de resolución de conflicto en general y de la conciliación en particular, convertidos, al igual que la oralidad, en una verdadera moda asociada a las reformas procesales. Tanto es así que en la práctica, la incidencia de la conciliación procesal en el resultado de las estadísticas asociadas a los factores de término de las causas laborales resulta ser demasiado relevante, Ilegando prácticamente al 50\% las que finalizan por esta vía ${ }^{3}$.

\footnotetext{
${ }^{2}$ Algunos operadores no sin razón señalan que el sistema de poderes ex officio del juez están, en primer lugar, destinados a que no haya juicio, a través de una acción agresiva en la etapa de conciliación.

${ }^{3}$ Esta información se obtuvo del Informe de gestión de la Defensoría laboral, Región del Maule (20102011). La estadística, si bien es de una región del país, está en concordancia con lo que sucede también en el resto del país. Anótese también que dicha cifra cubre también a los avenimientos.
} 
Tenemos, entonces, una nueva realidad en la cual la solución al conflicto laboral se logra, en un altísimo porcentaje, por la vía las conciliaciones ante el mismo Tribunal del Trabajo. La pregunta que cabe formular a este respecto es si esta situación y estadística es demostrativa de que las cosas están funcionando bien o, al contrario, reflejan un fenómeno que, si bien se ha tolerado hasta ahora por la mayoría de los intervinientes, evidencia al menos un problema o defecto en el adecuado funcionamiento de un modelo que debe siempre ser respetuoso de los principios básicos sobre los cuales debe levantarse todo proceso.

En este orden de ideas, y al hilo de lo recogido en la sentencia que nos sirve de justificación a estas líneas, empiezan a multiplicarse las opiniones de operadores del nuevo sistema que se refieren abiertamente y como una realidad con la cual hay que necesariamente convivir el hecho que los jueces presionan o emiten opiniones más allá de lo razonable para lograr acuerdos, ${ }^{4}$ logrando de esta forma mantener las estadísticas señaladas de cara a desahogar la labor jurisdiccional. Pues bien, más allá del discurso oficial que destacaría positivamente estas estadísticas señalando que mostrarían la salud del sistema instaurado, lo que se puede apreciar a partir de esta particular realidad, hace recordar la base ideológica fundamental de F. Klein ${ }^{5}$, famoso por su Ordenanza procesal civil austríaca de 1895, cual es, que el proceso es un mal social, y que como tal suponía una pérdida de tiempo y dinero con repercusiones en la sociedad y debía eliminarse con la máxima rapidez ${ }^{6}$. Este postulado ideológico sobre el proceso llevaría a la necesidad de resolver de modo rápido el conflicto, objetivo que sólo resultaría compatible con un juez dotado de grandes poderes que han de estar al servicio de garantizar fundamentalmente los más altos valores e intereses de la sociedad y del Estado.

Pues bien, por mucho que algunos pretendan asociar el nuevo proceso laboral a las nuevas tendencias del Derecho procesal, el antecedente recién anotado evidencia que a propósito de esta reforma nuestro legislador lo que hace, otra vez, es importar un modelo que ya ha sido probado en otras latitudes hace muchísimos años. El caso es que si se revisa y analiza seriamente la evolución de las cosas en esta materia, la crisis de la Justicia parece no haber

\footnotetext{
${ }^{4}$ Los operadores en general se refieren al ejercicio excesivo de las potestades públicas que la ley les confiere a los jueces para conciliar.

${ }^{5}$ En 1895 era guardasellos (ministro de justicia) del imperio Austro-Húngaro, desde donde impuso una nueva regulación procesal con mano de hierro y permanente vigilancia sobre los tribunales. Varios apuntan también a la reforma procesal de Klein como el comienzo de la exaltación de las virtudes de la oralidad y el rol del juez.

${ }^{6}$ Se ha afirmado: "La sociedad tiene un gran interés en sanar lo más rápido posible tales heridas sobre su propio cuerpo". SPRung, V., "Le basi del Dirittoprocessualecivile austriaco", Rivista di Diritto Processuale, № 1, 1979, p. 38.
} 
desaparecido en aquellos países que recogieron modelos como el descrito, sumando además el grave problema de la imposición del voluntarismo por sobre la racionalidad, que viene de la mano del diseño del juez especialmente poderoso en todos los extremos involucrados en un proceso, sean meramente procesales, o bien derechamente materiales, que puedan llegar a influir en el contenido de la sentencia. Se asume entonces que los jueces, al representar el rol del Estado en el proceso, asumen el deber de eficacia y justicia hacia las personas, por lo que en su labor "no pueden echar mano a cuestiones técnicas, o sutilezas, que posterguen el derecho a una tutela judicial efectiva" ${ }^{\prime 7}$.

En los modelos que se han inspirado en esta ideología, como es el caso de nuestro nuevo modelo procesal laboral, el reforzamiento de las potestades judiciales oficiosas se aprecia también en la actividad conciliatoria. De hecho, entre aquéllos que se ocupan de sostener las virtudes de este modelo, uno de los principios fundamentales sería el de la inmediación, dotando de amplia libertad y poderes al juez para intentar la conciliación entre las partes.

Esta amplia libertad que se dan los jueces en la función conciliatoria tendría su asidero en la norma del artículo 453.2 del C. del Trabajo, que señala que terminada la etapa de discusión, el juez de la causa deberá llamar a las partes a una conciliación, "sin que las opiniones que emita al efecto sean causal de inhabilitación". Además, según se ha dicho, se sustentaría en el diseño reforzado en sus potestades que el juez tiene en nuestro sistema: juez profesional, interviniente y con reforzadísimos poderes, ${ }^{8}$ que en los hechos se termina apoderando del proceso en desmedro de las partes. ${ }^{9}$ Cobra suma relevancia la inexistencia e insuficiencia de herramientas de control del accionar judicial oficioso, sobre todo teniendo en cuenta la amplia potestad pública explícita que el Código del Trabajo le ha entregado.

Con todo, es importante insistir en que la intervención del juez se produce con ocasión de una contienda entre las partes, y que las posturas o teorías del caso que se plantean establecen necesariamente los límites de su acción, y que existiendo estas posturas diversas, el juez debe situarse por sobre las partes, evitando que sus poderes públicos oficiosos, lo transformen en una parte más, debiendo existir lo que alguno ha denominado como el desinterés subjetivo

\footnotetext{
7 Gozaínı, O., Problemas actuales del Derecho procesal (garantismo vs. activismo judicial), Fundap, México DF., 2002, pp. 49-50.

${ }^{8}$ Basta leer las normas de los artículos 425 y siguientes del C. del Trabajo, para constatar que dentro de las ideas legislativas básicas el que el juez no sea sólo un actor más, sino que el principal protagonista del juicio.

${ }^{9}$ No es nada extraño presenciar casos en que el juez interroga, en primer lugar, o excluye pruebas sin mayores fundamentos, por considerar que no son pertinentes, necesarias, sobreabundantes u otra causa, prescindiendo absolutamente de la teoría del caso de las partes.
} 
de la jurisdicción. ${ }^{10}$ Esto, porque resulta en extremo relevante, en atención al respeto por el debido proceso, que las partes puedan enfrentarse en un plano de igualdad, evitando que el juez adopte como propia durante el juicio o adquiera la posición de una de las partes o, peor aún, tenga su teoría propia.

Tal como ya hemos señalado en diversos lugares, existiendo posiciones enfrentadas ante el juez, debe ser éste el que situado por encima de ellas, presencie y dirija la controversia ${ }^{11}$. Esta cuestión que es clave y esencial, apunta a indicarnos que los derechos de las partes en el proceso traen aparejado el deber del órgano jurisdiccional de llevar adelante el proceso, sino que además, cumplir en el ejercicio de sus poderes públicos explícitos de una serie de principios básicos que informan la intervención del juez y las partes en el proceso. Esto es tan relevante que si no se cumple, el juicio pasa a ser sólo un simulacro ${ }^{12}$.

No obstante, la realidad en el proceso laboral criollo es bien distinta. La existencia de un juez con este grado de poder, dificulta muchísimo a las partes controlar su actuar, más aún cuando la ley expresamente lo exime, al parecer, de toda inhabilidad por las opiniones que emite o pueda emitir durante la conciliación ${ }^{13}$. El escenario de control de las potestades del juez en el C. del Trabajo es absolutamente deficitario, y las normas prácticamente inexistentes, quedando en evidencia que el legislador quiso entregarle al juez un rol sin contrapesos, lo que, a nuestro juicio, sin lugar a dudas, afecta una noción de proceso que sea verdaderamente respetuosa de los postulados elementales ya enunciados, y que dan cuenta de un verdadero proceso.

En la función conciliatoria ocurre lo propio. Parece obvio que no es recomendable, prudente ni lícito que el juez manifieste sus opiniones durante el juicio, si esas opiniones manifiestan cierta postura que hace evidente cómo será su fallo. El panorama es más complejo todavía si revisamos la práctica generalizada de la Ilamada "conciliación especial", en las que el juez opina libremente durante el desahogo de la prueba o antes de las observaciones. Se aprecia entonces cómo el espacio de la conciliación, que debiera ser de discusión que busca armonizar y acercar a las partes para poner fin anticipado al

\footnotetext{
${ }^{10}$ Montero Aroca, J., Sobre la imparcialidad del juez y la incompatibilidad de funciones procesales, Ed. Tirant Lo Blanch, Valencia, 1999, pp. 186 y ss.

${ }^{11}$ Véase en esta línea de pensamiento: De la Oliva Santos, A.; Diez-Picazo Giménez, I.; Vegas Torres, J. Derecho Procesal: Introducción, $3^{\text {a }}$ Edición, Ed. Ramón Areces, Madrid, 2004.

${ }^{12}$ Véase: Alvarado Velloso, A., Garantismo procesal contra actuación judicial de oficio, Ed. Tirant lo Blanch, Valencia, 2005.

${ }^{13}$ Aunque para nosotros es evidente que no cualquier comentario u observación en el proceso de conciliación, se puede entender cubierto por este privilegio. Qué decir de las conciliaciones denominadas "especiales", no contempladas en la ley y que provocan que el juez intervenga el proceso, proponiendo a las partes un arreglo, que normalmente tiene ínsito el fallo del Tribunal.
} 
proceso, se ha transformado no pocas veces en un terreno donde el juez de la causa da cuenta de su postura, prácticamente entregando en forma anticipada su sentencia. Cabe destacar que este fenómeno ocurre más comúnmente en los procedimientos monitorios, lo que agrava más la situación descrita, dado que es el mismo juez el que va a resolver el caso en esa misma audiencia ${ }^{14}$.

Por ejemplo, y respecto a la sentencia, lo cierto es que durante la conciliación, o durante las audiencias, muchos jueces emiten opiniones que afectan notoriamente su debida imparcialidad y exceden con creces los principios de razonabilidad y prudencia mínimos que demuestren a las partes que están ante un juez realmente imparcial. Las partes, usualmente, se paralizan frente a esto, y ven desmoralizadas cómo el juez ya les dijo, sin haber siquiera recibido la prueba, cuál será su veredicto. Resulta que el juez que se excede en sus opiniones en la etapa de conciliación o durante la práctica de la prueba o que ejecutan el mecanismo denominado de la conciliación especial para prácticamente obligar a las partes a arreglar, sobrepasan con creces sus obligaciones y prohibiciones. Incluso algunos jueces (son pocos afortunadamente) hacen manifestaciones de referencia evidentes en el desarrollo de las audiencias, donde emiten pronunciamiento u opinión sobre cuestiones sometidas a su conocimiento, ${ }^{15}$ incluso fuera del período de conciliación.

Es la realidad en muchos juicios del trabajo, como consecuencia de una reforma que asume un modelo de juez muy reforzado en sus potestades ex officio, sin los necesarios contrapesos o contrapoderes para las partes. Los jueces adoptan, adquieren o se apropian del proceso, y participan como una parte más. Lo peor es que normalmente subsidian al litigante negligente, o se instalan en el lado del trabajador, provocando una asimetría evidente. ${ }^{16}$ En el tema de las conciliaciones, lo que está pasando es que durante el proceso, sin que las partes tengan mucha idea de hacia dónde el juez ha apuntado su razón, éste da cuenta de ciertas posturas expresas que anticipan su fallo en contra de

\footnotetext{
${ }^{14}$ No olvidemos que la mayoría de los juicios son monitorios, siempre una cifra superior al 50\%. Informe de gestión de la Defensoría laboral, Región del Maule (2010-2011).

${ }^{15}$ Galán González, C.,Protección de la Imparcialidad Judicial: Abstención y recusación, Ed.Tirant Lo Blanch, Valencia, 2005. Contiene un análisis acertado sobre la protección de la imparcialidad judicial y cómo estas manifestaciones de referencia efectivamente afectan al proceso y a las partes. Estas manifestaciones, en nuestros tribunales del trabajo, son cuestión de todos los días.

${ }^{16}$ Existe una cantidad de sentencias importantes donde los jueces manifiestan opiniones que escapan de la razonabilidad, y que demuestran ciertas preferencias, ideas o convicciones personales que escapan totalmente de lo que un juez profesional, preparado, competente e imparcial debería hacer. En esto estimamos relevante señalar que la independencia ideológica del juez (mal entendida), nos lleva a la figura del juez todopoderoso, a que dicha independencia en instancias como la conciliación, por ejemplo, provoca que pueda señalar lo que le parezca pertinente, perdiendo en muchos casos la imparcialidad en el conocimiento del juicio.
} 
una de ellas, o en contra de ambas, adoptando una teoría del caso propia. Los poderes judiciales oficiosos no pueden implicar una autorización para que el juez de la causa se exceda en su papel de tercero imparcial, dado que la ley le entrega esos poderes justamente para resguardar ese rol y no para abandonarlo. Los poderes no pueden entenderse como un permiso para adquirir el proceso en desmedro de las partes, por lo que las opiniones que emita el juez en el marco de la función conciliatoria no lo inhabilitarán en la medida que no impliquen una anticipación de su fallo o no demuestren ideas preconcebidas a favor de una u otra parte.

Lo cierto es que actualmente las partes carecen realmente de mecanismos de control del juez en lo que se refiere a sus reforzados poderes, y éste, en no pocos casos, se ha acostumbrado a intervenir de tal forma en el proceso, que puede afectarse su imparcialidad en forma real, tal como la Corte ha determinado que ha ocurrido en este caso. Así como en otros casos, cuando el juez se excede en sus potestades públicas, afectando a las partes, la oralidad en sí misma, pierde buena parte de su sentido y propósito, si no se acompaña de una serie de controles y contrapesos que permitan delimitar claramente el rol de las partes y del juez, la forma en que éste interviene en el proceso, en ejercicio de sus poderes oficios, y la oportunidad procesal que los ejecuta. ${ }^{17}$

A nuestro juicio, el tema en relación con los poderes oficiosos del juez laboral es simple, por mucho que a propósito de la reforma se hayan olvidado unos postulados que son elementales. El juez no debería tener mayor intervención en el juicio y sus opiniones durante la etapa de conciliación deberían necesariamente estar limitadas y restringidas por su rol de tercero en la disputa que deberá decidir. La imparcialidad del órgano jurisdiccional constituye una garantía procesal ${ }^{18}$, y tanto la imparcialidad objetiva como subjetiva deben inspirar y dirigir el actuar del juez en el proceso, a fin que las partes tengan el proceso más objetivo posible.Y esto no tiene que ver con la restricción de la libertad ideológica del juez en atención a su libertad de expresión. Debe entenderse de una vez que el juez se manifiesta a través de la sentencia y es en ésta dónde podrá plasmar sus ideas jurídicas, ideológicas, de experiencia y otras, pero no puede en el proceso exponer opiniones o verter juicios que afecten a una de las partes o ambas.

Entendemos que la legitimidad del actuar de todo juez se sustenta en la independencia y la imparcialidad, porque esa autonomía moral que debe tener

\footnotetext{
17 Podemos debatir si el actuar en específico fue o no desbordado, pero lo cierto es que la Corte sin atender mucho al hecho mismo, dio cuenta de un clamor subterráneo e hizo de este juez en especial una baja necesaria dentro del sistema, obviando como veremos una serie de normas.

${ }^{18}$ Rodríguez Fernández, Ricardo, La contaminación procesal. El derecho al juez imparcial, Ed. Comares, Madrid, 2000, pp. 17 y ss.
} 
el juez en su accionar le permite ejercer debidamente su rol jurisdiccional con la debida independencia.

Lo que acá revisamos también tiene que ver con el deber del juez en cuanto tercero, y a cómo su intervención exorbitante puede dañar el proceso. Las partes pueden resultar victoriosas o no en un juicio determinado, pero si no obtienen el resultado buscado y el juez se excedió en sus poderes oficiosos en el Ilamado a conciliación, emitiendo opiniones en un sentido gravoso para la teoría del caso de una de ellas, sin duda alguna que esa parte quedará con la convicción de haber sido juzgada por un tribunal sesgado y parcial. Eso que está ocurriendo en muchos procesos laborales debe evitarse a toda costa. El desprestigio de la función judicial no pasa únicamente por la demora o por los fallos que la opinión pública pueda estimar errados, o por la pugna constante entre este poder y el político, sino que atraviesa todos estos elementos y dice relación con la forma en que el juez en los procesos orales demuestra su independencia e imparcialidad.

Es por esto que la ley establece mecanismos para que el juez sea inhabilitado y recusado: el sistema aspira a un juez imparcial. Pero también el juez debería abstenerse de conocer de un caso que estima que lo afecta desde el punto de vista de su libertad de raciocinio, por cuanto tiene una opinión formada o simplemente porque tiene lugar alguna de las causales que están en la ley. Pero no existe norma que abarque las manifestaciones de referencia fuera del juicio o las expresiones que formule durante la conciliación que claramente marcan la línea argumental del juez y la forma en que finalmente podemos defendernos. ¿Tenemos un debido proceso si un juez ha manifestado durante la conciliación opiniones que pueden anticipar o vislumbrar la dirección de su fallo? ¿Existe un debido proceso si el juez ha manifestado en artículos, charlas o clases una determinada línea argumental? Estimamos que en estos casos, no tenemos un juicio justo, y no tenemos un debido proceso, con los estándares mínimos necesarios.

Si el juez se excede en sus poderes públicos explícitos, y se compromete espiritualmente con el proceso sea en forma previa o durante el juicio, lo que afecta es su imparcialidad, dado que el juzgador se compromete en el proceso más allá del interés objetivo en el caso, pasando a ser una parte más.

Pues bien, entusiasmado nuestro legislador con la doctrina que desde hace años postula un fuerte aumento de los poderes ex officio de los jueces de la mano del tránsito a un sistema oral, concretó la configuración de un juez con reforzadísimas potestades. Este papel judicial activo estaría justificado especialmente en los llamados "procesos sociales", donde estarían autorizadas estas reforzadas potestades, sobre todo por la necesidad de asistencia a la que se considera la parte más débil del proceso que, desde el Derecho Laboral, están contestes en denominar desigualdad compensatoria de las diferencias sociales, 
culturales y económicas. Se repite que se debe tomar conciencia que los jueces ya no son sólo la boca de la ley, sino también tienen responsabilidades sociales lo que justificaría su activismo. ${ }^{19}$ No sólo no podemos estar de acuerdo con esta posición, sobre todo cuando ese activismo se transforma en no pocas veces en un activismo ideológico ${ }^{20}$ relevante dentro del proceso que, finalmente, priva a las partes de la debida imparcialidad del juez, sino que, además de aceptarse esta idea que el juez en este tipo de procesos puede intervenir de forma libre y que sus poderes oficiosos en materia de conciliación particularmente lo liberan de toda prudencia, pudiendo opinar sin límites, resulta que finalmente las partes en el proceso carecerán de un proceso real, tal como hemos indicado.

La nueva normativa laboral, ha establecido vastos poderes de dirección formal y material del proceso, no habiendo límites claramente establecidos. No obstante esto, debemos tener claro y entender que ninguno de estos poderes es absoluto, sino que están sujetos necesariamente a restricciones. Estas restricciones deben partir del juez mismo, pero también las partes deben ejercer todos los derechos posibles en el proceso, que les permita asegurar un debido proceso y un juez imparcial. Lo que buscamos es revisar críticamente (sin autocomplacencia) este nuevo escenario con nuevos jueces, profesionales y especializados, con amplias potestades públicas explícitas, a fin de evitar actuaciones que afecten esta imparcialidad judicial, y que finalmente descuadran el sistema, haciéndolo asimétrico y con una mala percepción general, afectando la imagen de la Justicia y la seriedad de la función jurisdiccional.

Un sector de la doctrina procesal que se ha ocupado del tema de las potestades judiciales ha señalado que al establecer compatibilidad de funciones procesales, entre el juzgar y probar, se está afectando la imparcialidad del juez, porque se le exige al juez desplegar una actividad para la cual finalmente no se encuentra llamado. Es olvidarse incluso del desinterés objetivo de la jurisdicción, por cuanto se le exige al juzgador algo más que ser juez, lo que entendemos afecta la sustancia de la administración de justicia y la función jurisdiccional. ${ }^{21}$ Esto, en el aspecto específico de la conciliación tiene aún más relevancia, porque las partes ni siquiera han empezado a desahogar su prueba, y ya tienen clara la

\footnotetext{
${ }^{19}$ Peyrano, J. "El perfil deseable del juez civil del siglo XXI". En: Silva, J.; García, J.; Leturia, F. (Coords.), Justicia civil y comercial: una reforma pendiente. Bases para el diseño de la reforma procesal civil, Santiago, P. Universidad Católica de Chile, Universidad Autónoma de Madrid, Instituto Libertad y Desarrollo, 2006, pp. 789 y ss.

${ }^{20}$ Entendemos ideológico desde las ideas, no sólo con un tinte de carácter meramente político, sino que desde el punto de vista filosófico y sociológico que tiene que ver con las visiones fundamentales de la sociedad, el rol del proceso y de las partes y el juez.

${ }^{21}$ Montero Aroca, J.,Sobre la Imparcialidad del Juez y la Incompatibilidad de funciones procesales, VALENCIA, Ed. Tirant lo Blanch, 1999, pp. 186 y ss.
} 
postura del juez. Todavía más, es muy probable que el juez excluya o no prueba conforme a esas opiniones, lo que violenta el debido proceso en general, y el derecho de defensa en particular. ${ }^{22}$

Creemos indispensable reconocer límites a la actividad y conducta del juez en el ejercicio de sus poderes oficiosos, especialmente en lo que se refiere a la forma en que se pretende arribar a una conciliación. Es válido que en la lógica del nuevo sistema procesal laboral no todos los procesos deban llegar a juicio. Parece hasta saludable que sólo llevemos a juicio los casos complejos, de precedente, o aquéllos en que las partes no pueden efectivamente llegar a acuerdo, pero no parece razonable que se evite llegar a juicio ejerciendo los poderes oficiosos de un modo desbordado, ejecutando acciones dirigidas a emitir opiniones sobre el fondo del asunto.

\section{Cierre. Sobre la solución de la corte a la situación}

Ahora bien, sin perjuicio de lo señalado críticamente hasta aquí respecto a la actuación y conducta del juez a quo, tampoco parece razonable la solución a la que arribó la Corte de Apelaciones de Santiago. Llama nuestra atención cómo el Tribunal de alzada en este caso, con infracción del debido proceso, anula una sentencia, sobre hechos y con antecedentes proporcionados por las partes en el alegato, no señalados en los recursos, que no constan en los audios y respecto de los cuales no se ejerció ningún recurso ante el tribunal a quo.

En la sentencia que analizamos, resulta que la Corte de Apelaciones da cuenta de un actuar aparentemente indebido del juez, quien habría señalado en forma constante que fallaría en un sentido. El problema que ahora anotamos es que las partes nada dijeron durante esta audiencia, y no existe constancia de reclamo o recurso alguno sobre el particular; por el contrario, las partes llevan adelante el juicio en forma normal. ${ }^{23}$

Al hacerlo, la Corte de Apelaciones violenta el debido proceso, desde que anula una sentencia por los dichos de las partes en el alegato, que no constan en el audio, por supuestos actos cometidos por el juez, respecto de los cuales

\footnotetext{
22 Por ejemplo, recientemente en el juicio sobre la matanza de Breivik en Noruega, un juez fue inhabilitado por los comentarios que efectuó en la red social facebook, antes de ser juez designado en ese proceso. Ese nivel de rigurosidad para el ejercicio jurisdiccional es el que se espera de todo juez, a fin de garantizar a toda prueba la imparcialidad e independencia judicial, lo que resulta saludable para las partes y para el proceso. Véase: http://www.emol.com/noticias/internacional/2012/04/17/536045/separana-uno-de-los-jueces-del-caso-breivik-tras-comentario-en-facebook.html?utm_source=twitterfeed\&utm_ medium=twitter [visitado el 17/04/2012].

${ }^{23}$ Incluso vamos más allá, porque si bien puede ser discutible el actuar del juez a quo, no puede ser debatible, que el proceso tiene un orden y determinadas formalidades que deben ser respetadas y que entendemos que en este caso no se observaron.
} 
no interpusieron los recursos en audiencia que hubiese correspondido. ¿Actúa mal el juez de primera instancia? Efectivamente se desborda en sus potestades públicas, pero a pesar de ello no se aprecia actividad alguna de las partes en el sentido de protegerse frente a este supuesto accionar indebido, teniendo los mecanismos para ello. Peor aún, nos encontramos con una sentencia de la Corte de Apelaciones que falla sobre la base de los dichos de las partes, sobre un supuesto actuar indebido de un juez, siendo que la posibilidad de alegar aquello ya había precluido, no ejerciendo tampoco sus poderes oficiosos, cuando en este caso, precisamente los podría haber ejercicio si le parecía que existía algún vicio reparable por esa vía.

Recapitulando, debemos señalar que, si bien las escasas herramientas de control del actuar jurisdiccional, no sólo en el aspecto probatorio, hace que los jueces tengan libertad de acción y muy pocas restricciones en el ejercicio de sus poderes oficiosos, esas herramientas existen, son escuálidas, pero existen y deben ser utilizadas, al menos deben esgrimirse en el momento que la parte se siente afectada.

Lo que la parte recurrente alegó que ocurrió en este caso pasa con alguna regularidad (y es preocupante), pero llama bastante la atención que la Corte de Apelaciones de Santiago termine también afectando principios básicos de todo proceso al subsidiar al litigante negligente que no ejerció sus derechos en la instancia respectiva, lo que constituye un actuar errado, desde que el accionar del juez a quo si se estimaba excesivo, debió haber sido cuestionado e impugnado en el acto. Debemos insistir: si bien los mecanismos de control se reconocen exiguos, existen, y fueron esos mecanismos los que no fueron ejercidos. ${ }^{24} \mathrm{No}$ lo fue porque las partes no lo estimaron así, y luego, como un argumento nuevo, se esgrime esta situación en sede de nulidad. Esto violenta el debido proceso, ya que si las partes no ejercieron su derecho de alegar contra el juez supuestamente poco parcial, no lo pueden pretender hacer en sede de nulidad.

Dentro de la labor del tribunal de nulidad, está la de resguardar el ordenamiento jurídico e incluso tiene la potestad de poder anular por motivos distintos que los que han señalado las partes, porque ha detectado hechos diversos que ameritan anular la sentencia. Con todo, ese resguardo del debido proceso y del ordenamiento jurídico, en el marco y límites del recurso de nulidad laboral, implica un resguardo estricto, que debe darse para que las partes también tengan claro que deben ejercer sus derechos en forma oportuna, de modo tal, que de otra forma, estaríamos en el escenario que finalmente las partes no importan en el proceso, porque tanto el tribunal a quo como el de nulidad, adquieren el

${ }^{24}$ El Código Orgánico de Tribunales, en relación con el Código de Procedimiento Civil tienen mecanismos de control. 
proceso y determinan lo que es mejor para el mismo, afectándose sin duda el rol de tercero imparcial y entre partes que la Constitución Política le entrega. Es curioso que la Corte de Apelaciones de Santiago a pretexto de resguardar el debido proceso, lo termine vulnerando también, saltándose todo el orden consecutivo, y la preclusión que había operado. Entendemos el fin de la Corte y el objetivo de dar una señal potente frente a los excesos, pero el instrumento utilizado resulta errado.

La tolerancia de los intervinientes con el constante desborde de los jueces en el ejercicio de sus potestades públicas ex officio termina afectando la noción misma del debido proceso, pero se afecta también si llegamos a tolerar que las Cortes, a pretexto de resguardar dicha garantía central, revivan derechos fenecidos, y resuelvan con dichos de las partes que no obran en el proceso. Es deber de los operadores restringir y limitar el actuar de los jueces en la etapa de la conciliación, resguardando la imparcialidad y, finalmente, protegiendo el proceso de contaminaciones indebidas, vengan de donde vengan, pero el mecanismo que se debe usar debe ser el adecuado.

La Corte podía haber usado la potestad ex officio del artículo 479 del Código del Trabajo y, sin embargo, opta por una salida equivocada, dando lugar a unas alegaciones de las partes que no constan en el registro de audio, y que son alegadas recién en sede de nulidad, sin haber ejercido de manera alguna los derechos que la ley les confería a éstas. Parece más bien que la Corte de Apelaciones de Santiago quiso aprovechar esta instancia para entregar una señal a los jueces del trabajo, pero el mecanismo utilizado, insistimos, no resultó ser el correcto.

La Corte de Santiago al parecer tiene claro que el desborde de los jueces en el ejercicio de estos poderes públicos oficiosos, constituye un evidente riesgo que debe corregirse. Esta señal parece razonable y positiva en lo sustancial, pero no se puede descuidar, para ser coherentes, la manera en que se ejecute ese control por las partes en primera instancia, así como el mecanismo que finalmente utilice la Corte sea el legalmente procedente. De otro modo, estaremos siempre con la sensación de estar en presencia de simulacros de juicio que dependen de la voluntad del juez de turno y no de la voluntad de la ley. 
